Carmo, M. B. S. y Costa, S. M. F (2019): "Estudo do crescimento urbano de uma pequena cidade na Amazonia: uma abordagem metodológica", GeoFocus (Artículos), $n^{\circ} \quad 23, \quad$ p. $\quad 31-47 . \quad$ ISSN: $1578-5157$ http://dx.doi.org/10.21138/GF.537

\title{
ESTUDO DO CRESCIMENTO URBANO DE UMA PEQUENA CIDADE NA AMAZÔNIA: UMA ABORDAGEM METODOLÓGICA
}

\author{
MONIQUE BRUNA SILVA DO CARMO ${ }^{1}$, SANDRA MARIA FONSECA COSTA ${ }^{2}$ \\ Universidade do Vale do Paraiba \\ Av. Shishima Hifumi, 2911 - Urbanova - São José dos Campos - SP. Brasil \\ ${ }^{1}$ moniquebruna@ymail.com, ${ }^{2}$ sandra@univap.br
}

\section{RESUMO}

As transformações espaciais urbanas que vêm ocorrendo nas pequenas, médias e grandes cidades da Amazônia desde a década de 1970, têm sido bastante significativas. A maioria dessas cidades (mais de $80 \%$ ) são consideradas "pequenos aglomerados urbanos", com menos de 20 mil habitantes com pouco acesso à serviços de infraestrutura urbana. O presente artigo demonstra uma avaliação de uma metodologia de mapeamento do uso e ocupação do solo do município de Barcarena, utilizando técnica de classificação não-supervisionada de imagens LANDSAT de sensoriamento remoto, obtidas entre os anos de 1984 e 2010. Ao longo desse período, o município teve redução da área de floresta em $43.7 \mathrm{~km}^{2}(27 \%)$ e a área construída aumentou $26.7 \mathrm{~km}^{2}(334 \%)$. O mapeamento do uso e ocupação do solo de Barcarena possibilitou verificar a existência de duas realidades urbanas distintas, a cidade-sede de Barcarena, e o distrito Vila dos Cabanos considerando a existência de um paradoxo entre os diferentes urbanos de um mesmo município.

Palavras-chave: Uso e ocupação do solo, Amazônia, expansão urbana, sensoriamento remoto.

\section{STUDY OF URBAN GROWTH OF A SMALL AMAZON CITY: A METHODOLOGICAL APPROACH}

\section{ABSTRACT}

Urban spatial transformations that have occurred in small, medium and large cities of the Amazon Region have been quite significant since the 1970s. Most of these cities (over $80 \%$ ) are considered small urban areas, with less than 20 thousand inhabitants, with poor infrastructure, and most of them are dependent on public and forest resources. This paper discusses a methodology of mapping of the land use and land cover of a part of Barcarena municipality, using unsupervised classification technique of remote sensing LANDSAT images, obtained between 1984 and 2010. During this period, there was a deforestation of $43.7 \mathrm{~km}^{2}$ $(27 \%)$ and the urban area grew $26.7 \mathrm{~km}^{2}$ (334\%). The mapping of the land use of Barcarena 


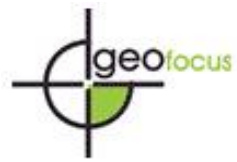

Revista Internacional de Ciencia y Tecnología de la Información Geográfica

International Review of Geographical Information Science and Technology

Carmo, M. B. S. y Costa, S. M. F (2019): "Estudo do crescimento urbano de uma pequena cidade na Amazônia: uma abordagem metodológica”, GeoFocus (Artículos), $n^{o} \quad 23, \quad$ p. $\quad 31-47 . \quad$ ISSN: $1578-5157$ http://dx.doi.org/10.21138/GF.537

municipality made possible to verify the existence of two distinct urban realities, the administrative city of Barcarena, and the District of Cabanos.

Keywords: Land cover, Amazon Region, urban growth, remote sensing.

\section{Introdução}

Segundo Becker (1985), a ocupação das cidades da Amazônia foi motivada por políticas governamentais, que deram condições para que a imensa floresta se tornasse urbanizada. Neste momento, mudanças estruturais foram observadas, principalmente, no que diz respeito à articulação espacial, uma vez que foram criados espaços estratégicos com a intenção de alavancar a economia, sob o ponto de vista da modernização. O Estado não tinha apenas o controle da terra como também era o próprio financiador do processo de ocupação e, desta forma, assegurava a instalação de grandes empreendimentos no território além de incentivar a migração em massa (Becker, 1998).

Como resultado do processo de urbanização, segundo Costa et al. (2009), observa-se o predomínio de cidades com menos de 20 mil habitantes na Região Amazônica que desempenham diferentes papéis diante da organização regional e local. Essas cidades são resultantes de transformações sócio-espaciais decorrentes dos últimos 30 anos. A intensificação do processo de ocupação dessas cidades ocorreu a partir da década de 1980, incentivada pelas ações do governo federal, que atraiu capital privado para a região e proporcionou a instalação de grandes projetos, sem que os mesmos suprissem os problemas de infraestrutura urbana presentes nas cidades da Amazônia (Schmink, 2012).

Grandes projetos foram pensados para as cidades da Amazônia com a intenção de investir na extração de recursos naturais, infraestrutura ou indústrias da transformação. Instalados na Região Amazônica, esses projetos incluem: a) projeto de exploração de minerometalúrgica, do qual fazem parte: Projeto Albrás-Alunorte- complexo para a produção de 800 toneladas/ano de alumina e 320000 ton/ano de alumínio, situado em Barcarena-Pará" (Maia e Moura, 1995). No caso das cidades que receberam grandes projetos, os meios tecnológicos se estabeleceram de forma única no território e se apropriaram das tradicionais formas de subsistência existentes na região (Vicentini, 2004), e com a implantação dos novos espaços. Grande parte da população foi atraída pelos grandes projetos, enquanto que a outra parte da população permaneceu sem acesso ao "novo" urbano.

O município de Barcarena, localizado no estado do Pará, é um exemplo de municípios que foram alvos dos grandes projetos e que, nesse caso, ao longo dos anos, passou a ter dinâmica urbana e rural mais intensa do que os padrões existentes nos municípios da Amazônia. A dinâmica urbana foi influênciada pela industrialização que alterou não somente a paisagem urbana e rural, mas também as relações sócio-espaciais do município. Considerando essa discussão, este artigo se propõe a apresentar uma metodologia de mapeamento do uso e ocupação do solo do urbano do município de Barcarena, utilizando dados e técnicas de Sensoriamento Remoto. Essa metodologia auxiliou na identificação dessa dinâmica urbana, por meio de uma análise multitemporal.

Optou-se por utilizar as técnicas de sensoriamento remoto para monitorar o crescimento urbano e as mudanças no uso e ocupação do solo, pois essas técnicas podem melhorar a compreensão do ambiente urbano e, sobretudo, permitir a elaboração de modelos que conduzam ao prognóstico de ocupação do espaço ao longo do tempo, integrando informações espaciais e sócio econômicas. As imagens de satélite são uma importante fonte de dados para os estudos 


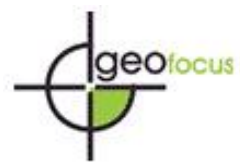

Carmo, M. B. S. y Costa, S. M. F (2019): "Estudo do crescimento urbano de uma pequena cidade na Amazonia: uma abordagem metodológica”, GeoFocus (Artículos), $n^{o} \quad 23, \quad$ p. $\quad 31-47 . \quad$ ISSN: $1578-5157$ http://dx.doi.org/10.21138/GF.537

urbanos das cidades da Amazônia, considerando que as mudanças urbanas ocorridas nos últimos anos. Por este motivo, optou-se por utilizar o método de classificação não-supervisionada para produzir o mapa de uso e ocupação do solo, a fim de identificar e monitorar a dinâmica urbana e as mudanças no espaço urbano de Barcarena-PA.

\section{2. Área de estudo}

A cidade de Barcarena está localizada na região estuarina do Rio Amazonas (Barcarena), próximo à Região Metropolitana de Belém, no Estado do Pará. Sua área total é de $1316.2 \mathrm{~km}^{2}$ (figura 1), o seu território é dividido em pequenas ilhas como: ilha das onças, do Ipiranga, Trambioca, Mucura, Arapari. As transformações ocorridas no município são exemplos da dinâmica socioespacial, iniciada na década de $1980 \mathrm{com}$ a chegada do complexo industrial da Albrás, principal responsável pelas transformações espaciais mais significativas. Segundo Nahum (2006), a partir da década de 1980, a divisão internacional do trabalho, na Amazônia, presenciou um avanço sobre o conhecimento dos efeitos espaciais do processo que reorganiza $o$ espaço mundial.

A população urbana do município de Barcarena, em 1980, representava $33.5 \%$ da população total. Entre 1980 e 1991, a população urbana cresceu e passou a representar $47.1 \%$ do total. Entretanto, em 2000, este percentual apresentou uma queda, passando a representar $45.0 \%$ do total e, em 2010, representava, aproximadamente, $36.0 \%$ da população total. A população rural, em contraposição, ao longo do mesmo período, passou de $66.0 \%$ do total para, aproximadamente, $64.0 \%$.

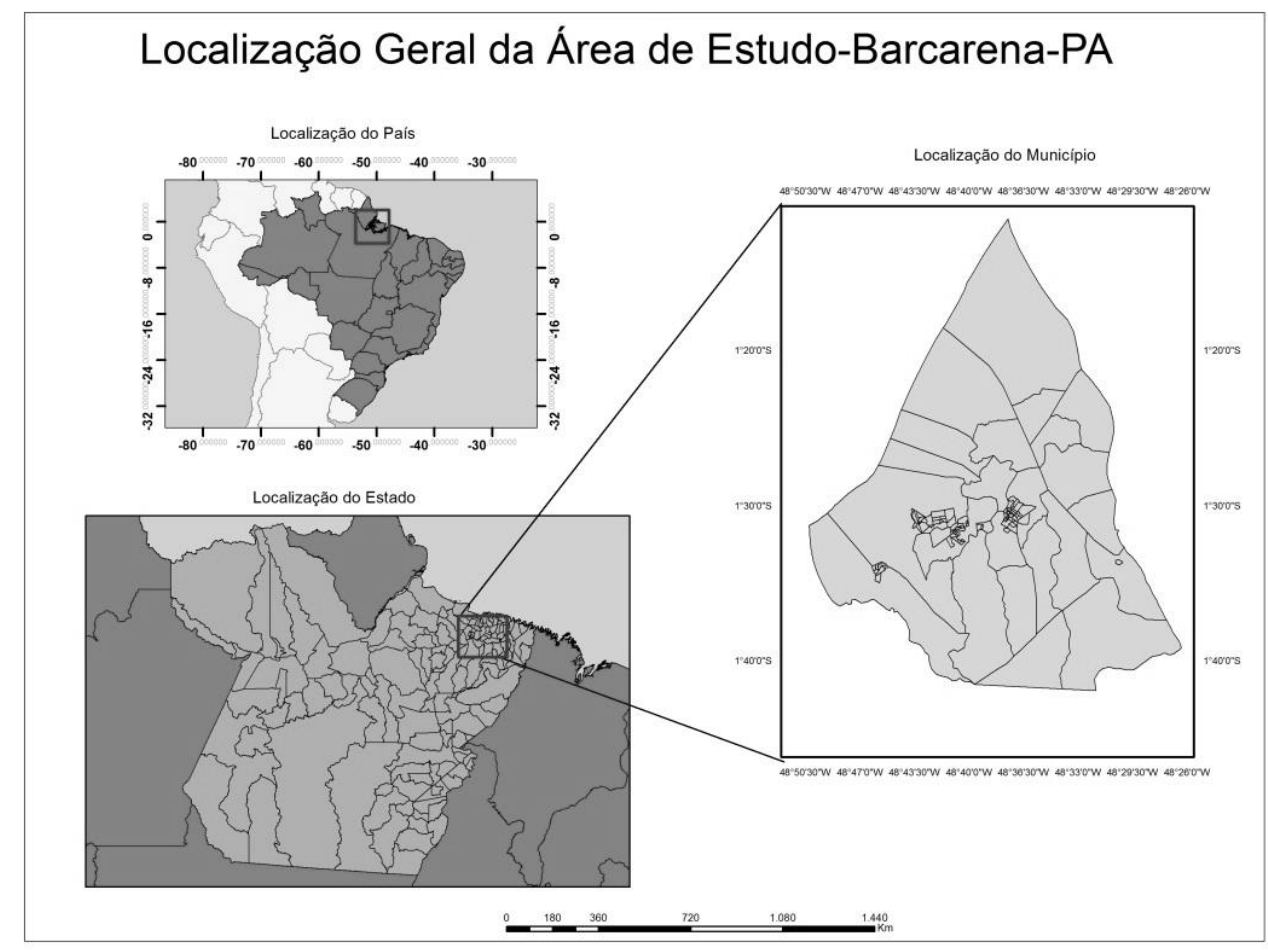

Fig. 1 - Mapa de Localização de Barcarena.

Fonte: autoras (2015) 
Carmo, M. B. S. y Costa, S. M. F (2019): "Estudo do crescimento urbano de uma pequena cidade na Amazonia: uma abordagem metodológica", GeoFocus (Artículos), $n^{\circ} \quad 23, \quad$ p. $\quad 31-47 . \quad$ ISSN: $1578-5157$ http://dx.doi.org/10.21138/GF.537

\section{Materiais e métodos}

Para o desenvolvimento desta pesquisa, foram seguidas as etapas descritas seguir.

\subsection{Coletas de Dados}

\subsubsection{Dados Coletados do IBGE}

Os dados agregados do Censo Demográfico do IBGE foram utilizados para fazer a análise comparativas das mudanças espaciais ocorrias nos setores urbanos e rurais, para que assim fosse possível diferenciar as áreas do município de Barcarena, entre os anos de 1980, 1990, 2000 e 2010. Com esses dados, foi possível construir gráficos para representar a dinâmica urbana do município.

Segundo dados do IBGE (2010), há incoerências em relação aos limites dos setores considerados urbanos e rurais do município de Barcarena. De acordo com esses dados, o setor que apresenta os melhores índices de infraestrutura urbana é categorizado como rural. Assim, para esse estudo, foram definidos como área de estudo: Vila dos Cabanos (área categorizada pelo IBGE, 2010, como rural) e Barcarena (sede administrativa do município). É importante ressaltar que a Vila dos Cabanos foi incluída nessa análise pelo fato de ter sido uma área planejada para atender as necessidades da empresa Albrás/Alunorte, e por possuir: área destinada à moradia dos trabalhadores da fábrica e por possuir melhor índice de infraestrutura, $o$ que chamou atenção por se tratar de uma área categorizada, pelo IBGE (2010), como rural.

\subsubsection{Imagens de Satélite}

Nesta pesquisa, foram utilizadas imagens de satélite, obtidas pelo sensor TM (Thematic Mapper) e ETM+ (Enhanced Thematic Mapper Plus), disponíveis nos satélites Landsat 5 e 7 , respectivamente, com resoluções espaciais de 30 metros. Algumas especificações técnicas desses sensores são apresentadas na tabela 1. Essas imagens foram utilizadas para mapear o crescimento da área urbana de Barcarena e para classificar o uso e ocupação do solo, entre 1984 e 2010 .

Para mapear as mudanças de uso e ocupação do solo na área de estudo foi selecionado área que engloba a indústria ALBRÁS (complexo industrial), a Vila dos Cabanos e a Barcarenasede (figura 2). Essa subcena totalizou, em área, aproximadamente, $226 \mathrm{~km}^{2}$. Os anos de 1984 , 1989, 2001 e 2010 foram selecionados para análise pois a indústria se instalou no município no final da década de 1980 e os anos subsequentes representam os reflexos da dinâmica urbana resultantes das ações dos grandes projetos. 
Carmo, M. B. S. y Costa, S. M. F (2019): "Estudo do crescimento urbano de uma pequena cidade na Amazonia: uma abordagem metodológica", GeoFocus (Artículos), $n^{\circ} \quad 23, \quad$ p. $\quad 31-47 . \quad$ ISSN: $1578-5157$ http://dx.doi.org/10.21138/GF.537

Tabela 1 Imagens de satélite utilizadas

\begin{tabular}{|c|c|c|c|c|}
\hline Satélite & Sensor & Orbita/Ponto & Data & $\begin{array}{l}\text { Bandas e } \\
\text { Comprimento de } \\
\text { Onda }(\mu \mathrm{m})\end{array}$ \\
\hline Landsat5 & $\mathrm{TM}$ & $223 / 61$ & 27/07/1984 & $\begin{array}{l}1-0.45 \text { a } 0.52 \mu \mathrm{m} \\
2-0.52 \text { a } 0.60 \mu \mathrm{m} \\
3-0.63 \text { a } 0.69 \mu \mathrm{m} \\
4-0.76 \text { a } 0.90 \mu \mathrm{m} \\
5-1.55 \text { a } 1.75 \mu \mathrm{m} \\
7-2.08 \text { a } 2.35 \mu \mathrm{m}\end{array}$ \\
\hline Landsat5 & $\mathrm{TM}$ & $223 / 61$ & $10 / 08 / 1989$ & $\begin{array}{l}1-0.45 \text { a } 0.52 \mu \mathrm{m} \\
2-0.52 \text { a } 0.60 \mu \mathrm{m} \\
3-0.63 \text { a } 0.69 \mu \mathrm{m} \\
4-0.76 \text { a } 0.90 \mu \mathrm{m} \\
5-1.55 \text { a } 1.75 \mu \mathrm{m} \\
7-2.08 \text { a } 2.35 \mu \mathrm{m}\end{array}$ \\
\hline Landsat7 & ETM+ & $224 / 61$ & 03/08/2001 & $\begin{array}{l}1-0.45 \text { a } 0.52 \mu \mathrm{m} \\
2-0.52 \text { a } 0.60 \mu \mathrm{m} \\
3-0.63 \text { a } 0.69 \mu \mathrm{m} \\
4-0.76 \text { a } 0.90 \mu \mathrm{m} \\
5-1.55 \text { a } 1.75 \mu \mathrm{m} \\
7-2.08 \text { a } 2.35 \mu \mathrm{m}\end{array}$ \\
\hline Landsat5 & $\mathrm{TM}$ & $224 / 61$ & 26/07/2010 & $\begin{array}{l}1-0.45 \text { a } 0.52 \mu \mathrm{m} \\
2-0.52 \text { a } 0.60 \mu \mathrm{m} \\
3-0.63 \text { a } 0.69 \mu \mathrm{m} \\
4-0.76 \text { a } 0.90 \mu \mathrm{m} \\
5-1.55 \text { a } 1.75 \mu \mathrm{m} \\
7-2.08 \text { a } 2.35 \mu \mathrm{m}\end{array}$ \\
\hline
\end{tabular}

Fonte: autoras (2015)

\subsection{Processamento das imagens}

A correção atmosférica foi utilizada para eliminar as imperfeições refletidas nas imagens de satélites como resultado da interação entre atmosfera e topografia. A escolha das imagens ocorreu de acordo com a qualidade radiométrica apresentada pelas imagens, incluindose nessa seleção, aquelas com baixa ou nenhuma cobertura no momento do imageamento dos sensores. As seis bandas $(1,2,3,4,5$ e 7$)$ de cada passagem foram utilizadas, conforme é possível observar na tabela 1. As imagens foram georreferenciadas em duas etapas: a primeira etapa o conjunto de bandas da primeira data foi georreferenciado com uma imagem padrão, e as outras imagens foram georreferenciadas a partir dessa primeira imagem. Foi gerado um recorte das imagens, para selecionar apenas o módulo espacial de interesse desse estudo e que engloba Barcarena-sede e Vila dos Cabanos (figura 2). 
Carmo, M. B. S. y Costa, S. M. F (2019): "Estudo do crescimento urbano de uma pequena cidade na Amazonia: uma abordagem metodológica”, GeoFocus (Artículos), $n^{\circ} \quad 23, \quad$ p. $\quad 31-47 . \quad$ ISSN: 1578-5157 http://dx.doi.org/10.21138/GF.537

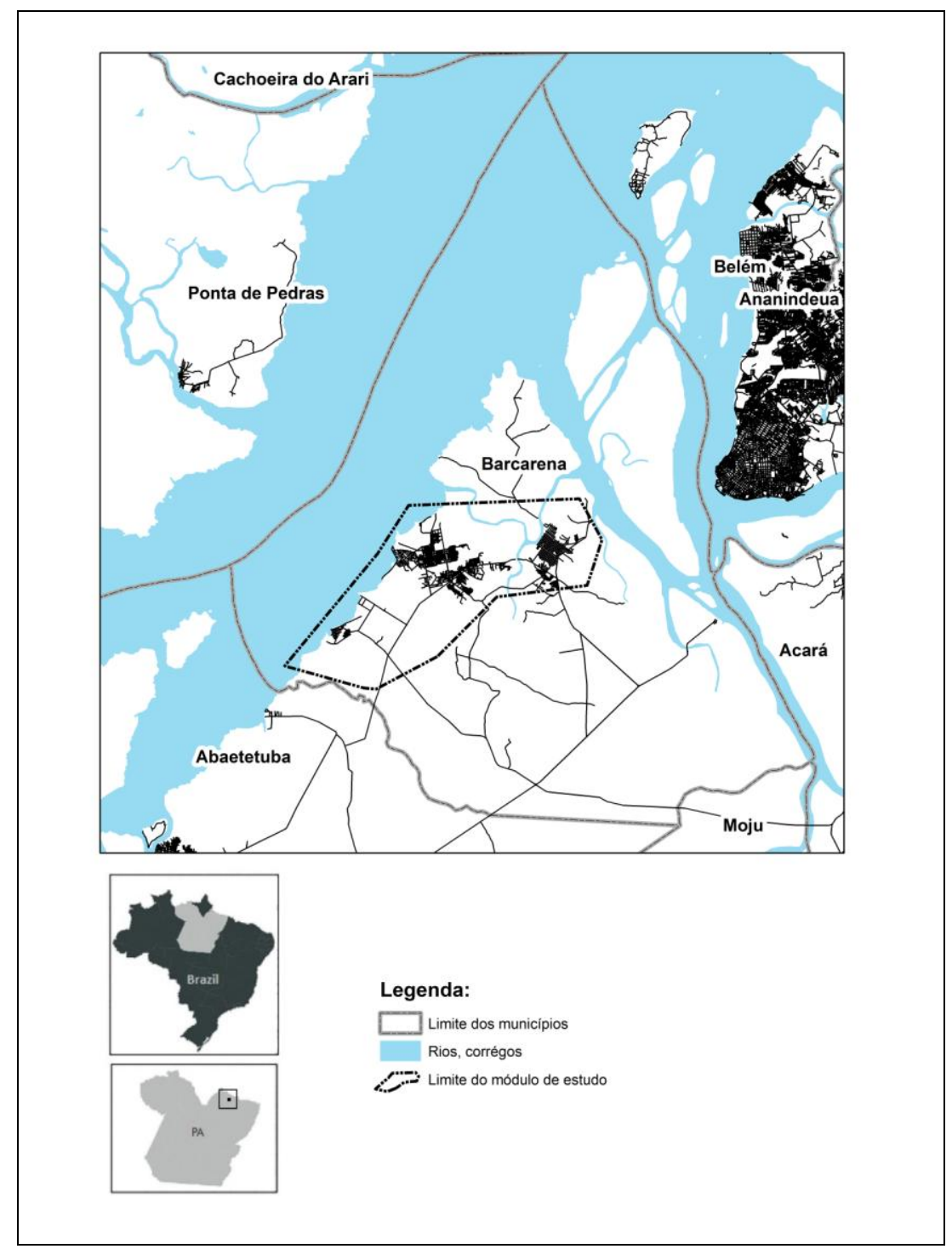

Fig. 2 - Módulo/subcena selecionada para análise nesse estudo

Para a correção atmosférica, foi adotado o método ATCOR (Atmospheric and Topographic Correction for Satellite Imagery) que permite normalizar as imagens com base no valor da reflectância e radiância. Para isso, foi necessário fornecer algumas informações das imagens obtidas como: o dia, mês e ano da aquisição das imagens landsat, o tipo de sensor, calibração e nível de elevação. Este tipo de correção permite excluir neblinas (haze), nuvens, reduz ou remove a influência da iluminação atmosférica, promovendo um melhoramento nos resultados dos algoritmos na detecção dos objetos e possibilitando recuperar os parâmetros físicos da superfície. Este método foi adotado por ser o mais indicado em aplicações de analises multitemporais e de cobertura do solo (figura 3). 


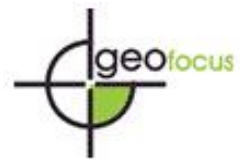

Carmo, M. B. S. y Costa, S. M. F (2019): "Estudo do crescimento urbano de uma pequena cidade na Amazônia: uma abordagem metodológica”, GeoFocus (Artículos), $n^{o} \quad 23, \quad$ p. $\quad 31-47 . \quad$ ISSN: $1578-5157$ http://dx.doi.org/10.21138/GF.537

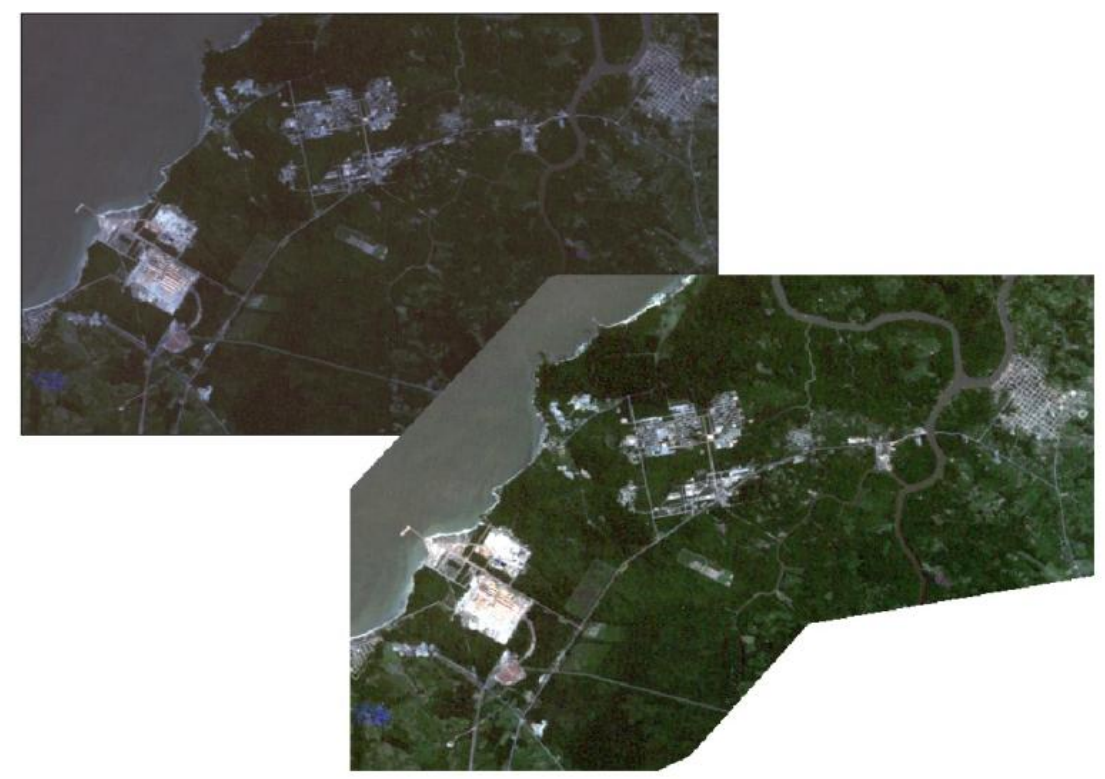

Fig.3 - Correção Atmosférica e Recorte da Área de Estudo.

Fonte: autoras (2015).

\subsubsection{Registro de Imagens}

O registro das imagens foi realizado por meio do software do ERDAS Imagine (2014), durante o qual houve uma transformação geométrica que relaciona as coordenadas da imagem (linha e coluna) com coordenadas geográficas (latitude e longitude) de um mapa. Segundo alguns autores (Novo, 1992, Longley et al., 2006, Mather, 2005), essa é uma técnica que torna as coordenadas geográficas conhecidas num dado sistema de projeção. Essa transformação na imagem elimina as distorções existentes, causadas durante o processo de obtenção da imagem, sejam ocasionadas por imperfeições presentes no sistema do sensor ou pela imprecisão do posicionamento da plataforma. Para o conjunto de imagens de cada ano, foram coletados pontos de controle necessários para sobrepor à imagem que foi utilizada como base para georrefereciamento das demais.

\subsubsection{Imagem de Transição}

Para certificar-se de que as imagens registradas estavam posicionadas geograficamente, foi gerado uma imagem de transição, resultante de uma sobreposição das imagens dos quatro períodos (1984, 1989, 2001 e 2010). Essa imagem apresenta, de forma sintética, as mudanças espaciais ocorridas no espaço urbano ao longo de todos os anos.

\subsubsection{Definição das Classes de Uso e ocupação do solo}

Foi realizado um mapeamento do uso e cobertura do solo para estabelecer as principais mudanças ocorridas na subcena de estudo, entre 1984 e 2010, ou seja, quantificar as transformações espaciais resultantes do crescimento urbano. Segundo Lillesand et al. (2004), "land use relates to the human activity or economic function associated with a specific piece of land (...) land use could be described as urban use, residential use, or single family residential use". 


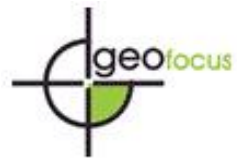

Carmo, M. B. S. y Costa, S. M. F (2019): "Estudo do crescimento urbano de uma pequena cidade na Amazônia: uma abordagem metodológica”, GeoFocus (Artículos), $n^{\circ} \quad 23, \quad$ p. $\quad 31-47 . \quad$ ISSN: 1578-5157 http://dx.doi.org/10.21138/GF.537

Para este mapeamento, optou-se por utilizar a técnica de classificação não supervisionada. De acordo com Novo (1992), "na classificação não-supervisionada, os pixels de uma imagem são alocados em classes, sem que o usuário tenha conhecimento prévio da existência. Este procedimento permite que o analista conheça a distribuição de pixel por classes espectrais". Para Gonçalves et al. (2008) "a classificação não-supervisionada baseia-se no princípio de que o algoritmo computacional é capaz de identificar por si só as classes dentro de um conjunto de dados. Esse tipo de classificação é frequentemente realizado através de métodos de agrupamentos" (Gonçalves et al., 2008, p.18).

A classificação foi gerada no software Erdas Imagine (2014), utilizando um algoritmo de classificação não supervisionada, denominado "ISODATA", e, a partir da classificação, obteve-se o resultado de 20 classes, que foram reagrupadas, resultando em 5 classes finais de uso e ocupação do solo: Floresta, Vegetação Secundária, Água, Superfície Construída e Solo Exposto.

Antes de finalizar a classificação e obter a imagem de transição, foram coletados 30 pontos de controle por classe, em um total de 150 pontos, no Google Earth (as imagens de alta resolução do Google Earth, para essa área de estudo pertencem ao ano de 2010), de forma a certificar que cada classe seria classificada da forma correta (figura 4). Após a classificação das imagens dos anos de 1984, 1989, 2001 e 2010, foi gerado uma imagem de transição, sendo esta imagem a composição das 5 datas.

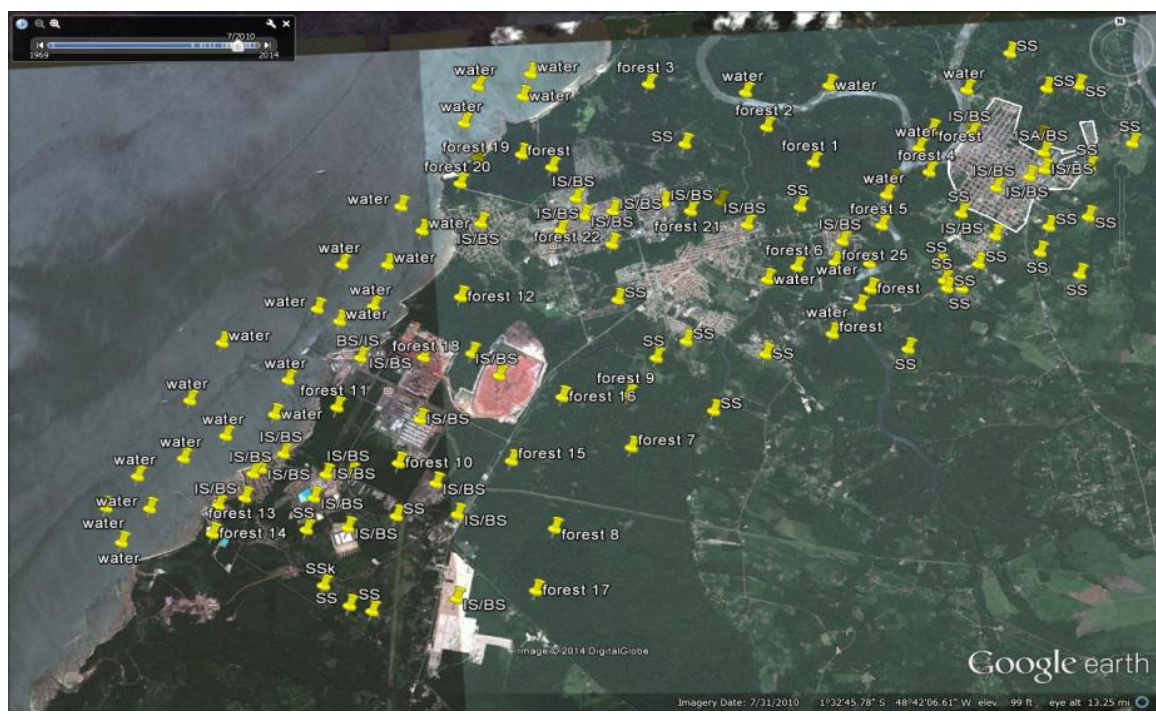

Fig. 4 - Coleta dos pontos para confirmar as classes escolhidas.

Fonte: autoras (2015)

\section{O crescimento urbano e a instalação da indústria no município de Barcarena}

A estruturação e dinâmica urbana, presente em Barcarena-PA, foi, e ainda é influenciada pela presença do processo de industrialização, que alterou a tradicional paisagem urbana, típica de uma de uma cidade da Amazônia. A estruturação espacial foi decisiva para a nova formação econômica do município no âmbito local, regional e nacional. Castro (1995) afirma que, a partir da década de 1980, pela cobiça internacional em conjunto com a atuação do Estado, influenciou-se, diretamente, o modo de vida urbano das cidades que receberam os grandes projetos industriais. 


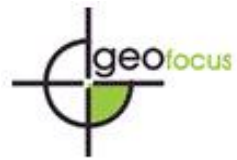

Carmo, M. B. S. y Costa, S. M. F (2019): "Estudo do crescimento urbano de uma pequena cidade na Amazônia: uma abordagem metodológica”, GeoFocus (Artículos), $n^{\circ} \quad 23, \quad$ p. $\quad 31-47 . \quad$ ISSN: 1578-5157 http://dx.doi.org/10.21138/GF.537

Esse processo de modernização do espaço, que teve início na década de 1980, possibilitou a instalação da empresa Alunorte/Albrás, resultando em transformações espaciais significativas, tais como: investimentos em infraestrutura, desmatamento de áreas para a construção e ampliação do complexo industrial e a criação de um plano urbanístico que deveria abrigar a infraestrutura que serviria para atender as necessidades dos trabalhadores da empresa, construção de estradas que interligam a indústria a outros locais do município e com municípios vizinhos, a construção e ampliação de portos para escoamento do alumínio, construção de casas em núcleos para abrigar os trabalhadores das empresas, investimentos em infraestrutura e tecnologia que atendessem as necessidades da indústria.

Para a análise dessas transformações, levou-se em consideração quatro períodos: 1984, 1989, 2001 e 2010. O ano de 1984 foi essencial para nos mostrar que foi a partir da instalação da empresa que o município começou a ser reestruturado e resultou em novas formas de uso e ocupação. Os demais períodos, como 1991, 2001 e 2010, foram importantes, pois possibilitaram identificar para onde a cidade cresceu nos últimos anos após a instalação da empresa. Com essas datas, foi possível identificar, por meio da análise multitemporal, os reflexos das atividades industriais e econômicas ao longo dos anos e como isso refletiu diretamente no espaço urbano. As imagens classificadas podem ser observadas na figura 5 e as áreas ocupadas por cada classe, em cada ano, encontram-se na tabela 2.

Tabela 2 - Porcentagem das classes de uso e ocupação do solo nos anos de 1984-2010

\begin{tabular}{|c|c|c|c|c|c|c|c|c|}
\hline & \multicolumn{2}{|c|}{1984} & \multicolumn{2}{|c|}{1989} & \multicolumn{2}{|c|}{2001} & \multicolumn{2}{|c|}{2010} \\
\hline Classes & $\begin{array}{l}\text { Área } \\
\left(\mathbf{k m}^{2}\right)\end{array}$ & $\%$ & $\begin{array}{l}\text { Área } \\
\left(\mathbf{k m}^{2}\right)\end{array}$ & $\%$ & $\begin{array}{l}\text { Área } \\
\left(\mathbf{k m}^{2}\right)\end{array}$ & $\%$ & $\begin{array}{l}\text { Área } \\
\left(\mathbf{k m}^{2}\right)\end{array}$ & $\%$ \\
\hline $\begin{array}{l}\text { Floresta } \\
\text { Vegetação }\end{array}$ & 163.5 & 72.3 & 162.7 & 72.0 & 143.9 & 63.7 & 119.8 & 53.1 \\
\hline Secundária & 0.8 & 0.4 & 2.5 & 1.1 & 7.1 & 3.1 & 21.3 & 9.4 \\
\hline $\begin{array}{l}\text { Água } \\
\text { Superfície }\end{array}$ & 43.1 & 19.0 & 39.6 & 17.5 & 43.7 & 19.4 & 42.6 & 18.9 \\
\hline $\begin{array}{l}\text { Construída } \\
\text { Solo }\end{array}$ & 8.0 & 3.5 & 14.8 & 6.6 & 29.2 & 12.9 & 34.7 & 15.3 \\
\hline Exposto & 10.6 & 4.8 & 6.4 & 2.8 & 2.1 & 0.9 & 7.6 & 3.3 \\
\hline Total & 226.0 & 100.0 & 226.0 & 100.0 & 226.0 & 100.0 & 226.0 & 100.0 \\
\hline
\end{tabular}

Fonte: autoras (2015).

Em 1984, iniciou-se as atividades da indústria e foram observadas mudanças espaciais resultantes, tais como a abertura de arruamentos, e tudo que estava ligado à indústria, que eram praticamente inexistentes no município e a paisagem ainda era bem típica das cidades ribeirinhas. Identificou-se que, neste período, $72.3 \%$ do uso e ocupação do solo eram de florestas, $0.4 \%$ era ocupado com vegetação secundária, $19.0 \%$ com água, $3.5 \%$ do total era ocupada com superfície construída e $4.8 \%$ foram classificados como solo exposto. Grande parte do solo exposto estava inserido em área de expansão da indústria. $\mathrm{O}$ solo exposto, existente nesse ano, não se relaciona obrigatoriamente, com a derrubada de floresta para instalação da indústria. Essa afirmação só seria possível se tivéssemos uma imagem de anos anteriores.

Em 1989, a área ocupada pelas florestas não se alterou de forma significativa, pois ocupava $72.0 \%$ da área total, e nem tampouco a área ocupada por vegetação secundária, $1.1 \%$ e água $17.5 \%$. A superfície construída aumentou $6.8 \mathrm{~km}^{2}$, representando $6.6 \%$ do total da área da subcena, o que resultou em um aumento de 85 \%, em área, em relação a 1984. No ano de 1991, 
Carmo, M. B. S. y Costa, S. M. F (2019): "Estudo do crescimento urbano de uma pequena cidade na Amazônia: uma abordagem metodológica”, GeoFocus (Artículos), $n^{\circ} \quad 23, \quad$ p. $\quad 31-47 . \quad$ ISSN: 1578-5157 http://dx.doi.org/10.21138/GF.537

grande parte da população estava concentrada em áreas de expansão urbana, ou seja, nos novos espaços reestruturados. Esse período foi marcado pela diminuição da população rural e aumento da população urbana.

No ano de 2001, houve um crescimento desordenado, resultando no surgimento de novas áreas de ocupações na Vila dos Cabanos. Barcarena (sede), núcleo considerado urbano pelo IBGE, cresceu em área, mas não de forma tão significativa quanto a Vila dos Cabanos. No ano de 2001, considerando a área da subcena analisada, $63.7 \%$ era área ocupada com florestas, ou seja, houve uma diminuição de $11 \%$ em relação à área ocupada anteriormente. A área de vegetação secundária não obteve mudanças significativas, assim como os corpos d'água mantiveram quase que a mesma porcentagem da área da subcena. A grande alteração é verificada na classe superfície construída, que apresentou um incremento de $14.4 \mathrm{~km}^{2}$, representado um aumento de 97 \%, em relação a 1991.

No ano de 2010, as mudanças que ocorreram foram significativas e mostraram, como resultado, as transformações provocadas pela indústria. Entre os anos de 1984 e 2010, houve $27 \%$ de perda de florestas e $334 \%$ de crescimento de área construída. Em 2010, a áreas de florestas ocupava $53.1 \%$ da área, a vegetação secundária $9.4 \%$, a classe água $18.9 \%$, a superfície construída $15.3 \%$ e o solo exposto $3.3 \%$.

O mapa final de sobreposição foi elaborado (figura 5), a partir dessas classificações, tendo sido mantidas as classes descritas a seguir, em função de sua importância para análise:

- Desmatamento: áreas que sofreram perda de floresta;

- Pavimentação: áreas construídas, sejam elas por casas, arruamentos, etc.

- Vegetação Secundária: classes que identificam áreas desmatadas ou de vegetação secundária. 
$\bigoplus^{\text {dgeo }}$
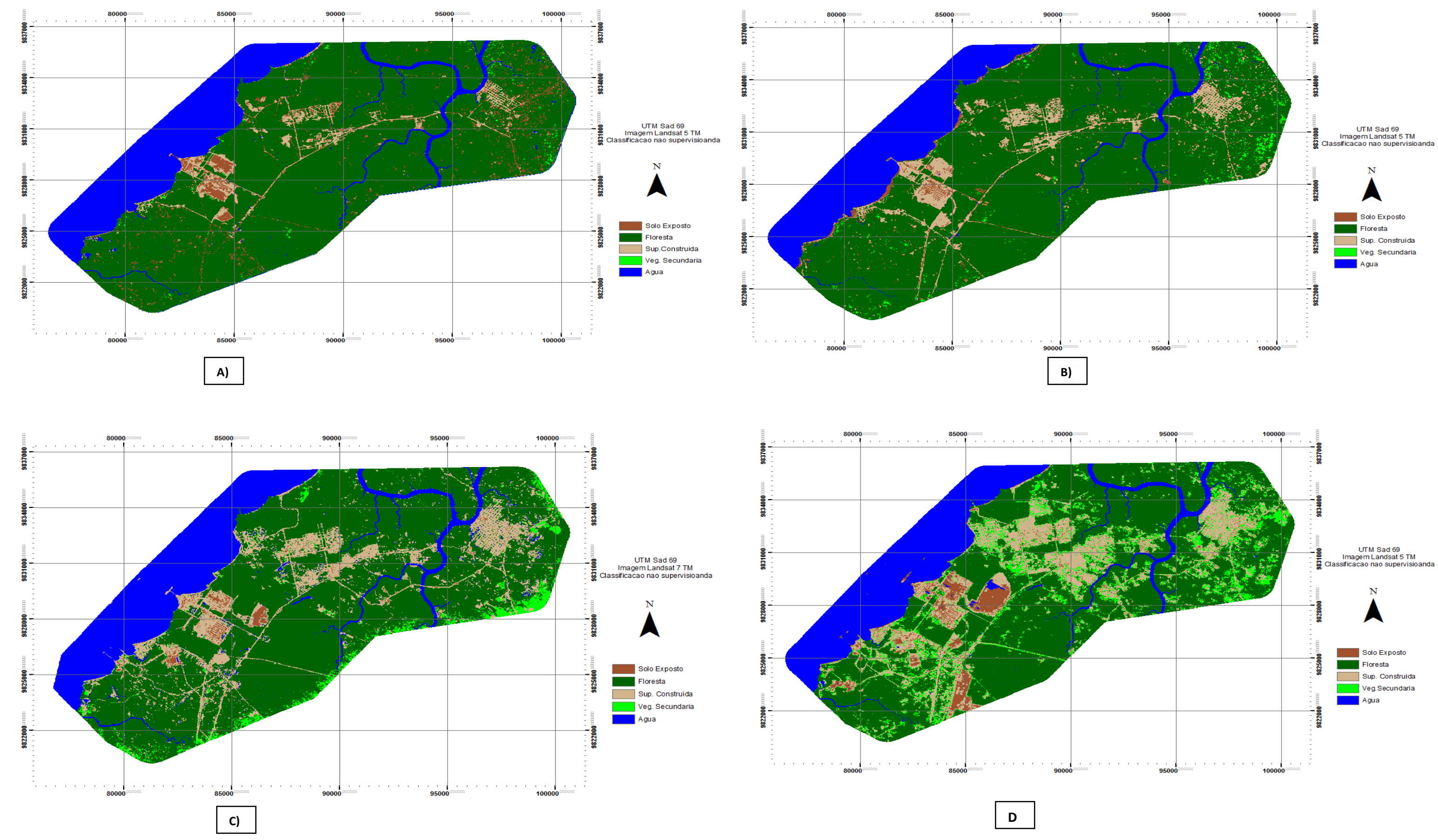

Fig. 5. Mapa de Uso e Ocupação do Solo: a) 1984, b)1989, c) 2001 e d) 2010. 


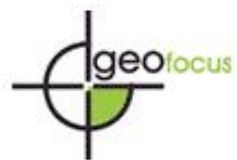

Carmo, M. y Costa, S. (2019): "Estudo do crescimento urbano de uma pequena cidade na Amazônia: uma abordagem metodológica", GeoFocus (Artículos), $n^{o} \quad 23, \quad$ p. $\quad 31-47 . \quad$ ISSN: 1578-5157 http://dx.doi.org/10.21138/GF.537

Utilizando-se essa informação, foram analisadas as mudanças ocorridas nos dois núcleos urbanos principais do município, ou seja, a Vila dos Cabanos e Barcarena (sede). Essa imagem de sobreposição foi gerada, para verificar se os resultados apresentados representavam a realidade da mudança, para o ano de 2010. Como mencionado na metodologia, foram coletados 30 pontos por classe, para certificar se cada classe foi classificada da forma correta, tendo sido gerada uma matriz de erros, que é um método para representar as coincidências e os erros de omissão e inclusão, entre a verdade terrestre e o resultado da classificação. A matriz de erro resultou em $95 \%$ de acerto (tabela 3 ).

Tabela 3 - Matriz de erro

\begin{tabular}{|c|c|c|c|c|c|c|c|c|}
\hline & & \multicolumn{5}{|c|}{ ISODATA } & & \multirow{2}{*}{$\begin{array}{l}\text { Exatidão } \\
\text { do } \\
\text { ISODATA }\end{array}$} \\
\hline & CLASSE & Floresta & $\begin{array}{l}\text { Vegetação } \\
\text { Secundária }\end{array}$ & Água & $\begin{array}{l}\text { Superfície } \\
\text { Construída }\end{array}$ & $\begin{array}{c}\text { Solo } \\
\text { Exposto }\end{array}$ & Total & \\
\hline \multirow{6}{*}{ 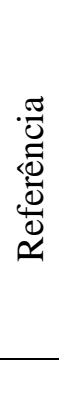 } & Floresta & 29 & 1 & 0 & 0 & 0 & 30 & $96.6 \%$ \\
\hline & $\begin{array}{l}\text { Vegetação } \\
\text { Secundária }\end{array}$ & 2 & 28 & 0 & 0 & 0 & 30 & $93.3 \%$ \\
\hline & Água & 0 & 0 & 29 & 1 & 0 & 30 & $96.6 \%$ \\
\hline & $\begin{array}{l}\text { Superfície } \\
\text { Construída }\end{array}$ & 0 & 2 & 0 & 27 & 1 & 30 & $90.0 \%$ \\
\hline & $\begin{array}{l}\text { Solo } \\
\text { Exposto }\end{array}$ & 0 & 0 & 0 & 1 & 29 & 30 & $96.6 \%$ \\
\hline & Total & 31 & 30 & 29 & 29 & 31 & & \\
\hline
\end{tabular}

Fonte: autoras (2015).

Considerando a matriz de erros, observa-se que as classes Floresta e Solo Exposto tiveram mais erro de inclusão, e a classe Superfície construída teve a maior porcentagem de omissão. Esses resultados se referem às características espectrais dos alvos pertencentes a essas classes. Em relação à Floresta, $6 \%$ dos pontos de controle acusaram classificação como vegetação secundária, o que é justificável, pela proximidade espectral dessas duas classes, assim como $3 \%$ dos pontos de controle acusaram classificação de áreas de vegetação secundária como floresta e $6 \%$ como superfície construída, pois essa classe seria intermediária entre as duas situações de uso. A classe superfície construída apresentou erro de omissão de $10 \%$, pixels que foram classificados como solo exposto e vegetação secundária. Entretanto, apesar dessas ocorrências, a matriz de erro demonstrou que a classificação obtida se aproxima da realidade.

Em relação às mudanças, foi possível observar que as construções que surgiram ao longo dos anos, proporcionaram uma nova face ao tecido urbano da cidade. Aquela caracterização de pequena cidade, dependente dos recursos da floresta sem ruas asfaltadas e casas de palafita, foi substituída pela pavimentação e casas de alvenarias, além da construção de imóveis residenciais, entre outros estabelecimentos.

A paisagem do município foi modificada e novos serviços urbanos surgiram ao longo dos anos. A paisagem ligada a uma ideologia de modernização foi se expandindo pelo município, mas não de forma homogênea, apenas nos locais de interesse dos setor público e privado receberam essa modernização, como foi o caso da Vila dos Cabanos, local em que está concentrado o maior índice de infraestrutura urbana, atendendo as demandas da empresa como também a população que mora na Vila dos Cabanos. Essas paisagens urbanas e rurais se misturam, não sendo perceptível mais a característica de espaço rural, atrasado, com pastos, plantações etc. Nessa nova paisagem se confundem o rural e o urbano e o urbano com o rural (Carmo, 2015). A existência do complexo industrial de Alumínio, em Barcarena, mostra que, certamente, a Vila dos Cabanos não seria tão diferente das demais vilas do município de Barcarena, ou possivelmente não existiria. 


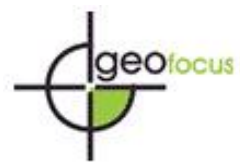

Carmo, M. y Costa, S. (2019): "Estudo do crescimento urbano de uma pequena cidade na Amazônia: uma abordagem metodológica", GeoFocus (Artículos), $n^{o} \quad 23, \quad$ p. $\quad 31-47 . \quad$ ISSN: 1578-5157 http://dx.doi.org/10.21138/GF.537

Nas imagens classificadas, referentes aos anos de 1984 e 1989, é possível identificar o início da intensa transformação espacial. Algumas áreas foram desmatadas para a implantação de pavimentação que ligaria a indústria à Vila dos Cabanos (figura 6a) como também para a ampliação da empresa e a construção e ampliação do porto, entre os anos de 1989 e 1990, o que criou uma nova demanda por infraestrutura no local. Também podemos observar o crescimento significativo de Barcarena - Sede (figura 6b).
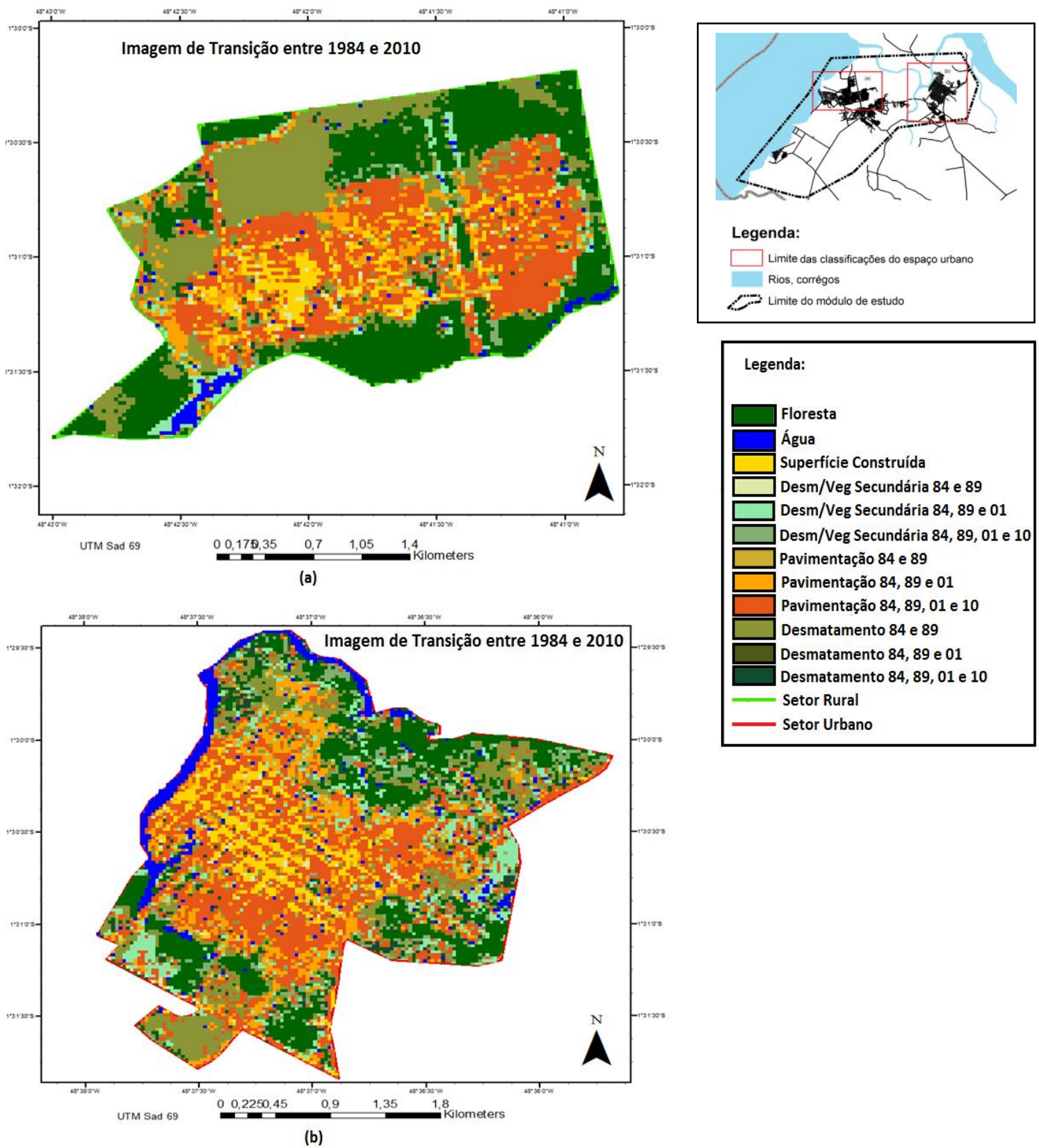

Fig. 6 - Mapa de Uso e Ocupação do Solo, considerando a delimitação dos setores censitários urbanos e rurais (IBGE, 2010): (a) Vila dos Cabanos; (b) Barcarena - Sede

Fonte: autoras (2015). 


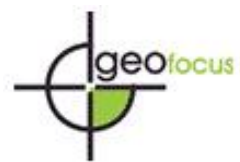

Carmo, M. y Costa, S. (2019): "Estudo do crescimento urbano de uma pequena cidade na Amazônia: uma abordagem metodológica", GeoFocus (Artículos), $n^{o} \quad 23, \quad$ p. $\quad 31-47 . \quad$ ISSN: 1578-5157 http://dx.doi.org/10.21138/GF.537

Entre os anos de 2001 e 2010, o que mais chamou atenção nos mapas de transição foi a expansão urbana. Mesmo considerando que a Vila dos Cabanos foi, e ainda é categorizada é um espaço categorizado pelo censo do IBGE (2010) como setor rural, a sua expansão acompanhou o crescimento do da população urbana.

As mudanças ocorridas na Vila dos Cabanos, entre os anos de 1984 e 2010, foram mais intensas com relação à classe "pavimentação" (gráfico 1). Apesar de ter $12.3 \%$ da superfície construída, essa classe, nesse período, teve um aumento de $51.5 \%$ em relação a área total transformada. Em Barcarena - Sede observa-se um crescimento, porém, de forma não tão significativa quanto ao que ocorreu na Vila dos Cabanos. Na sede, a classe "pavimentação", no mesmo período, cresceu $26.8 \%$ em relação a área total transformada.

Gráfico 1 - Porcentagem de mudança de uso e ocupação do solo (1984 a 2010).

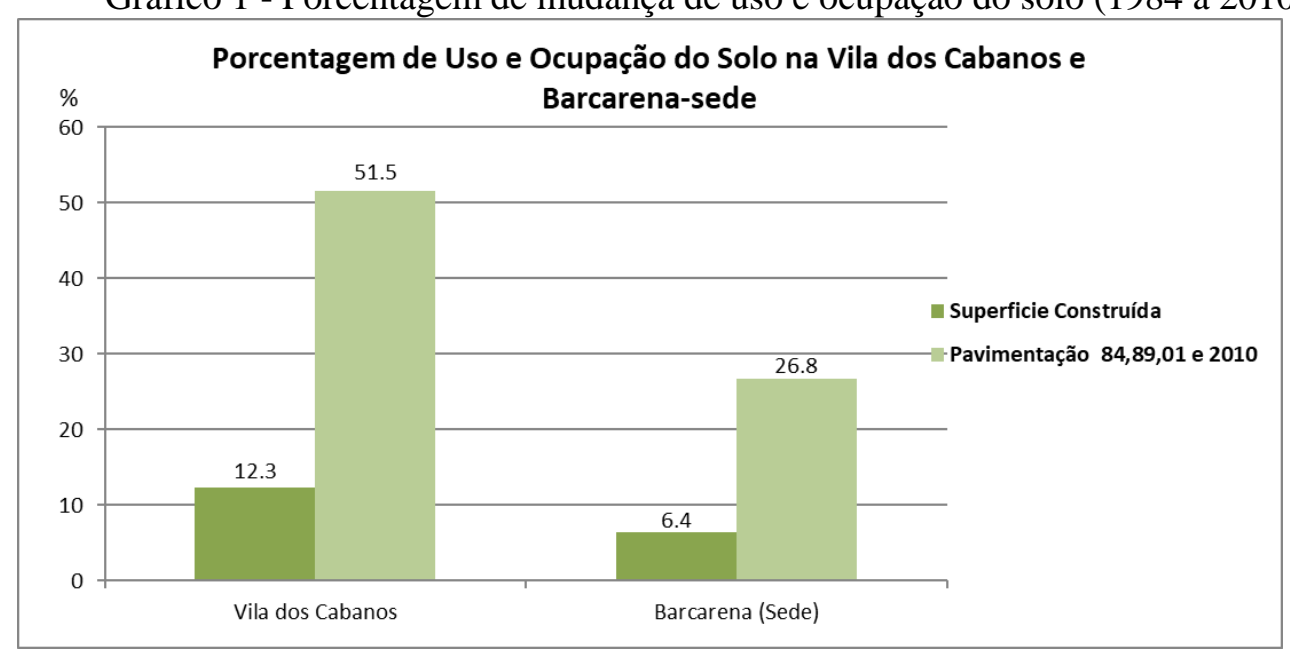

Essas transformações demonstram que o crescimento da área urbana foi mais intenso na Vila dos Cabanos, área categorizada segundo o censo do IBGE (20100 como rural, do que em Barcarena (sede) e reforça o que foi mencionado anteriormente que as mudanças na Vila dos Cabanos foram motivadas, principalmente, pela implantação do complexo industrial. No que diz respeito à classe de floresta, a área ocupada por florestas é mais significativa em Barcarena-sede $(18.1 \%)$ do que na Vila dos Cabanos $(0.1 \%)$, assim como as demais classes, apresentadas no gráfico 2 .

De acordo com os dados dos Censos (IBGE, 2010), entre 1980 e 1991, a população urbana apresentou uma taxa de crescimento de mais de $200 \%$, enquanto a população rural apresentou uma taxa de crescimento de $82 \%$. Entre 1991 e 2000, a população urbana continuou a apresentar taxas positivas de crescimento, entretanto não tão intenso quanto no período anterior (33\%). Entre 2000 e 2010, a população urbana cresceu apenas $26 \%$ no período e a população rural mais de $73 \%$.

É possível observar os paradoxos por parte das definições dos setores urbanos e rurais e de perceber que há uma singularidade entre os urbanos de Barcarena. Essa situação pode ser observada nas fotografias obtidas em campo, Vila dos Cabanos e Barcarena (sede). Na figura 7, as imagens retratam cenas da Vila dos Cabanos, setor considerado rural pelo Censo de 2010. Na figura 8, imagens de Barcarena - Sede, considerada área urbana.

Uma análise comparativa, considerando as fotografias das figuras 7 e 8 , observa-se uma urbanização mais próxima das metrópoles, na Vila dos Cabanos (figura 7), representada pela verticalização e existência de condomínios fechados. Enquanto que em Barcarena-sede (figura 8) uma paisagem típica de uma cidade ribeirinha, da floresta, com as palafitas e trapiches (portos) 


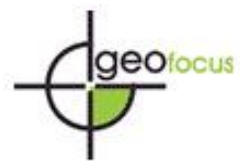

Revista Internacional de Ciencia y Tecnología de la Información Geográfica International Review of Geographical Information Science and Technology

Carmo, M. B. S. y Costa, S. M. F (2019): "Estudo do crescimento urbano de uma pequena cidade na Amazônia: uma abordagem metodológica”, GeoFocus (Artículos), $n^{o} \quad 23, \quad$ p. $\quad 31-47 . \quad$ ISSN: 1578-5157 http://dx.doi.org/10.21138/GF.537

Gráfico 2 - Porcentagem de mudança de uso e ocupação do solo (1984 a 2010).
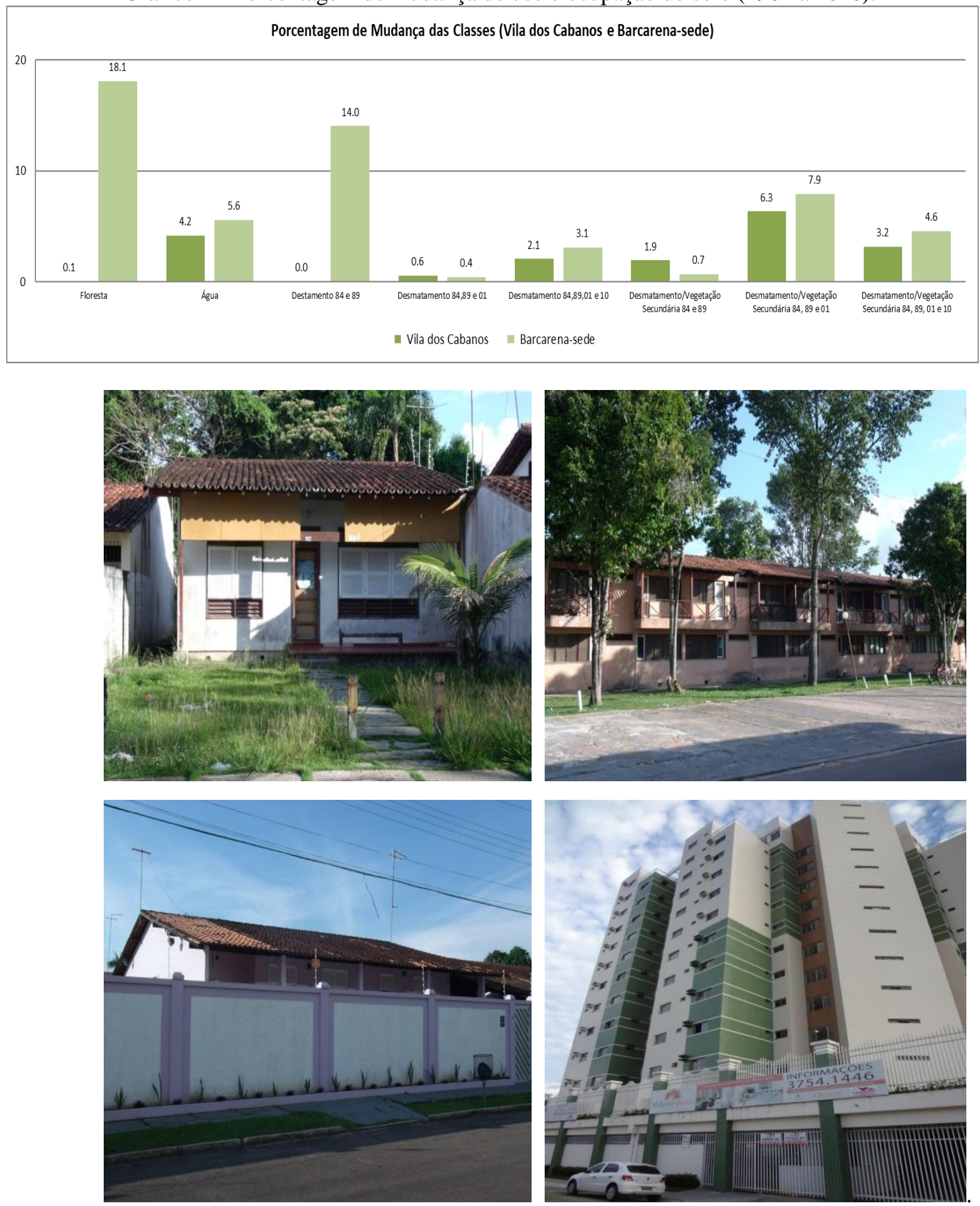

Fig. 7 - Moradia construída pela fábrica Alunorte/Albrás destinadas aos trabalhadores, e a Verticalização de áreas próximas à Vila dos Cabanos, núcleo considerado rural segundo o IBGE (2010)

Fonte: Fotografias obtidas pelas Autoras (2014). 


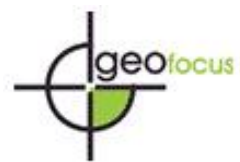

Carmo, M. B. S. y Costa, S. M. F (2019): "Estudo do crescimento urbano de uma pequena cidade na Amazonia: uma abordagem metodológica”, GeoFocus (Artículos), $n^{\circ} \quad 23, \quad$ p. $\quad 31-47 . \quad$ ISSN: 1578-5157 http://dx.doi.org/10.21138/GF.537
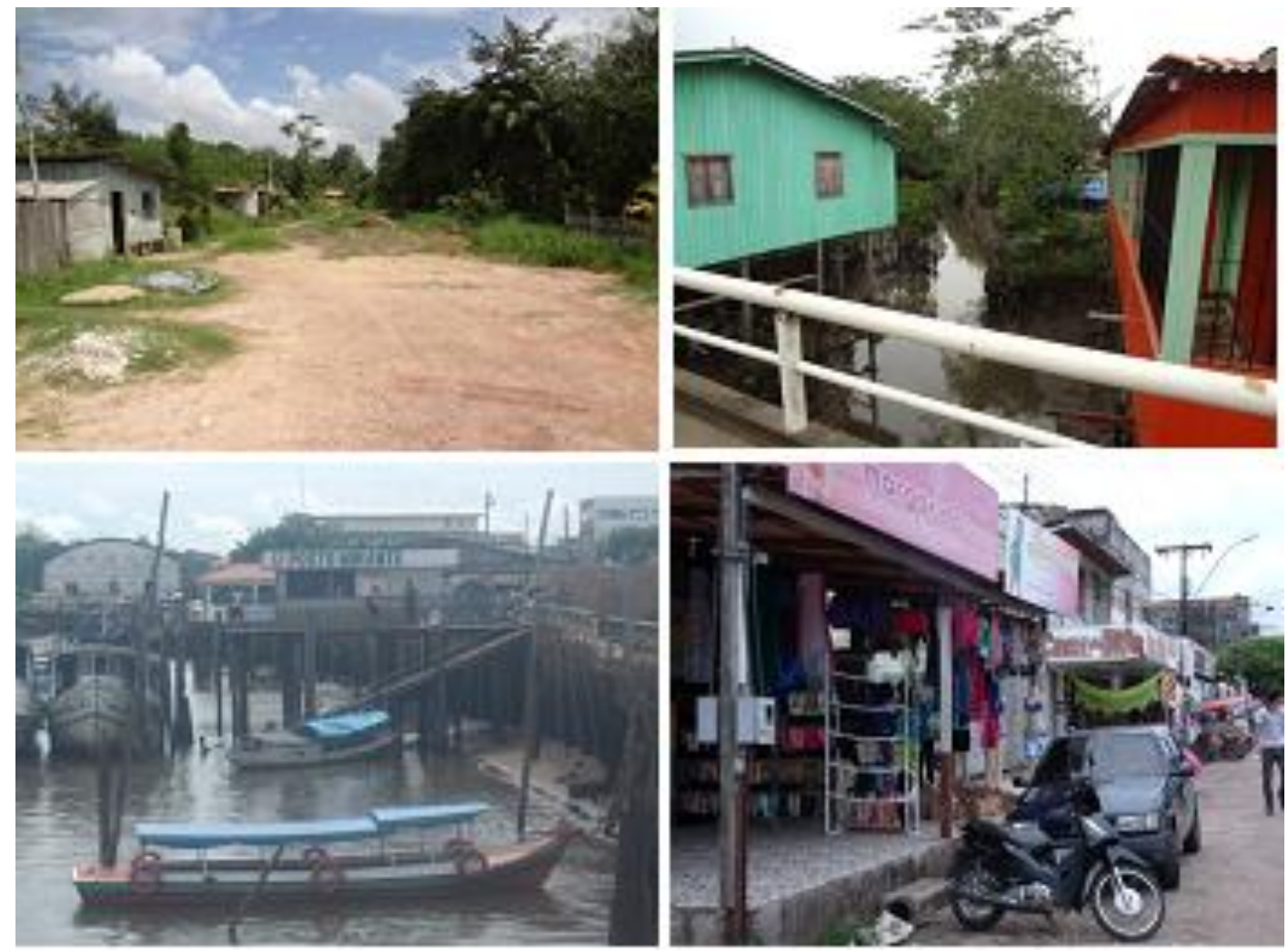

Fig. 8 - Infraestrutura urbana -Barcarena (sede), moradias de palafitas e o comércio local. Fonte: Fotografias obtidas pelas autoras (2014).

\section{Considerações finais}

O uso de técnicas de sensoriamento remoto, por meio da ferramenta "classificação não supervisionada" proporcionou a obtenção de uma análise sobre a compreensão da dinâmica espacial ocorrida no município de Barcarena, desde a implantação do Complexo da ALBRÁS. Esta ferramenta nos auxiliou a identificar que a Vila dos Cabanos, considerada rural, faz parte de um urbano estendido, sendo a área que mais se expandiu nos últimos anos, resultante das ações da indústria. Essa paisagem, alterada pela dinâmica econômica-espacial regional, está ligada a uma ideologia do Estado de modernização, que se expandiu pelo município formando paradoxos entre o espaço urbano e rural.

Como se pode observar, o mapeamento realizado demonstrou que houve um crescimento de mais de $300 \%$ de área construída, essas construções, em sua maior parte localizadas na Vila dos Cabanos. Esse fenômeno demonstra que sem a presença da indústria, que se instalou há 30 anos, certamente Barcarena não seria tão diferente das demais cidades da Amazônia ribeirinha e, provavelmente, o núcleo mais "modernizado" não existiria.

Esta reorganização espacial resultou em duas realidades espaciais bem distintas dentro do mesmo município, uma área recebeu fortes investimentos de forma que atendessem apenas aos interesses do capital. Este espaço classificado como "rural", agrega a maior infraestrutura e as melhores condições sócio- econômicas em relação à área sede do município. Isto é visível tanto em relação aos aspectos sociais como espaciais.

Compreendemos que a instalação da Indústria ocorreu para concretizar um plano e não um planejamento que contemplasse a cidade como um todo. 


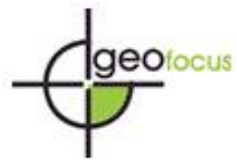

Carmo, M. B. S. y Costa, S. M. F (2019): "Estudo do crescimento urbano de uma pequena cidade na Amazônia: uma abordagem metodológica”, GeoFocus (Artículos), $n^{o} \quad 23, \quad$ p. $\quad 31-47 . \quad$ ISSN: 1578-5157 http://dx.doi.org/10.21138/GF.537

O uso e ocupação do solo do município de Barcarena nos mostra duas realidades bem distintas, e assim podemos afirmar que é possível discutir um modelo de planejamento urbano e regional em conjunto com a ferramenta do sensoriamento remoto de forma que nos auxilie a identificar essas problemáticas usuais, tanto nas cidades da Amazônia assim como nas demais cidades brasileiras.

\section{Agradecimentos}

Agradecemos a FAPESP (Fundação de Amparo à Pesquisa do Estado de São Paulo) pelo apoio financeiro fornecido a esta pesquisa, por meio da concessão de bolsa e do financiamento a projeto regular, assim como ao $\mathrm{CNPq}$ (Conselho Nacional de Desenvolvimento Científico e Tecnológico) pelo suporte financeiro por meio de bolsa de produtividade. Agradecemos também ao Departamento de Antropologia da Universidade de Indiana, nos Estados Unidos e ao ACT (Anthropological Center for Training and Research on Global Environmental Change) pelo apoio técnico e infraestrutura fornecida a essa pesquisa.

\section{Referências bibliográficas}

Becker, B. K. Fronteira e Urbanização Repensadas. Revista Brasileira de Geografia, v. 51, n, 3- 4, p. 357-371, 1985.

Becker, B. K. A. Especificidade do Urbano na Amazônia: Desafios para políticas Públicas Consequentes. Estudo elaborado para a Secretaria de Coordenação dos Assuntos da Amazônia. Legal - Ministério do Meio Ambiente. 1998, 60p.

Carmo, M. and Bruna S. A. Singularidade do urbano de Barcarena, como cidade ribeirinha da região Amazônica. Dissertação de Mestrado em Planejamento Urbano e Regional, na Universidade do Vale do Paraíba. São José dos Campos, 2015.

Castro, E. Industrialização, Transformações Socias e Mercado de Trabalho. In: Castro, E.; Moura, E. A. F.; MAIA, M. L. S. Industrialização e Grandes Projetos: desorganização e reorganização do espaço. Belém: Editora Universitária. UFPA, 1995

Costa, S. M. F., Brondizio, E., Montoia, G, H. M. As Cidades Pequenas do Estuario do Rio Amazonas: Crescimento Urbano e Rede Sociais da cidade de Ponta de Pedras, PA. In: Simposio Nacional de Geografia Urbana-SIMPURB, 11, 2009. Anais. Brasilia: UNB, 2009.

Gonçalves, M. L., Andrade Netto, M. L., Zullo JR, J., Costa, J. A.F. Classificação nãosupervisionada de imagens de sensores remotos utilizando redes neurais auto-organizáveis e métodos de agrupamentos hierárquicos. In: Revista Brasileira de Cartografia no. 60/01, Abril 2008.

IBGE (Instituto Brasileiro de Geografia e Estatística). [Material Institutional]. Disponível em <http://www.ibge.gov.br>, acessado em 2010.

Lillesand, T. M., Kiefer, R. W., Chipman, J. W. Remote Sensing and Image Interpretation, $5^{a}$ Ed. New York: John Wiley \& Sons, 2004, 763 pp.

Longley, PA, Goodchild, M F; Maquire, D J, Rhind, D W. Geographic information science and systems. New Jersey, EUA: John Wiley \& Sons, 2006. 


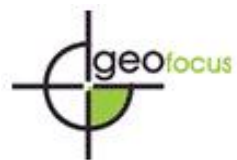

Carmo, M. B. S. y Costa, S. M. F (2019): "Estudo do crescimento urbano de uma pequena cidade na Amazônia: uma abordagem metodológica", GeoFocus (Artículos), $n^{\circ} \quad 23, \quad$ p. $\quad 31-47 . \quad$ ISSN: 1578-5157 http://dx.doi.org/10.21138/GF.537

Mather, Paul M. Computer Processing of Remotely-Sensed Images: An Introduction, 3rd Edition. West Sussex: Wiley, 2005.

Maia, M. L. S.; Moura, E. A. F. A divisão Internacional do Trabalho e a Nova Indústria do Alumínio na Amazônia. In: Castro, E.; Moura, E. A. F.; Maia M. L. S. Industrialização e Grandes Projetos: desorganização e reorganização do espaço. Belém: Editora Universitária. UFPA, 1995.

Novo, E. M. L. de M. Sensoriamento remoto: princípios e aplicações. São Paulo: Edgard Blücher, 1992

Nahum, J.S. O Uso do Território Em Barcarena: Modernização e Ações Políticas Conservadoras. [s/r]. Tese de Doutorado em Geografia, no Instituto de Geociências e Ciências Exatas. São Paulo, 2006.

Schmink, M. Conflitos sociais e a formação da Amazônia. Belém: Edu.ufpa, 2012.

Vicentini, Y. Cidade e História na Amazônia. Paraná. UFPA. 2004 
